\title{
Prevalence of target organ damage in hypertensive subjects attending primary care: C.V.P.C. study (epidemiological cardio-vascular study in primary care)
}

\author{
Athanasia Papazafiropoulou ${ }^{1,2^{*}}$, Efstathios Skliros ${ }^{1,3}$, Alexios Sotiropoulos ${ }^{1,2}$, Christos Papafragos $^{1,3}$,
} Aristofanis Gikas ${ }^{1,4}$, Ourania Apostolou ${ }^{1,2}$, Hariklia Kaliora ${ }^{1,3}$ and Charalambos Tountas ${ }^{1}$

\begin{abstract}
Background: Except for the established risk factors, presence of target organ damage has an important role in the treatment of hypertensive subjects. The aim of the present study was to estimate the prevalence of target organ damage in primary care subjects.

Methods: This multi-centre, cross-sectional survey of 115 primary care physicians recruited 1095 consecutive subjects with hypertension: 611 men (55.8\%); and 484 women (44.2\%). A detailed history for the presence of cardiovascular disease and a thorough clinical examination was performed to each subject.

Results: Of the total study population, $44.5 \%(n=487)$ had target organ damage (33.0\% had left ventricular hypertrophy, 21.8\% increased carotid intima media thickness, $11.0 \%$ elevated plasma creatinine levels and $14.6 \%$ microalbuminuria). Target organ damage was more prevalent in males than in females ( $P=0.05)$. In addition, males had more often increased carotid intima media thickness than females $(P=0.009)$. On the contrary, females had more often microalbuminuria $(P=0.06)$ than males. No differences were observed between the two genders regarding left ventricular hypertrophy $(P=0.35)$ and elevated plasma creatinine levels $(P=0.21)$. Logistic regression analysis showed associations between target organ damage and dyslipidemia $(P<0.001)$, presence of metabolic syndrome $(P=0.005)$, diabetes $(P<0.001)$ and coronary artery disease $(P<0.001)$.

Conclusion: A significant proportion of hypertensive subjects in primary care had documented associated target organ damage, with left ventricular hypertrophy being the most prevalent target organ damage.
\end{abstract}

Keywords: Primary care, hypertension, target organ damage, left ventricular hypertrophy

\section{Background}

Arterial hypertension has been recognized as one of the major cardiovascular risk factors and management of hypertensive subjects still remains a challenge for the clinicians [1]. Except for the established risk factors [age, gender, family history of cardiovascular disease, smoking, obesity, dyslipidemia and diabetes mellitus (DM)], presence of subclinical target organ damage (TOD) (left ventricular hypertrophy, carotid atheromatosis and renal

\footnotetext{
* Correspondence: pathan@ath.forthnet.gr

'Hellenic Association of Research and Continuing Education in Primary Care, Athens, Greece

Full list of author information is available at the end of the article
}

impairment) has an important role in the treatment of hypertensive subjects and the prevention of cardiovascular disease $[2,3]$.

It has been showed that subclinical TOD is a marker of increased cardiovascular morbidity and mortality [4-9]. Hypertensive subjects with left ventricular hypertrophy $(\mathrm{LVH})[4]$, increased carotid intima media thickness (IMT) [5] and microalbuminuria [6-9] show increased cardiovascular risk. In addition, hypertensive subjects with apparent macrovascular disease [cerebrovascular disease, coronary artery disease (CAD) and peripheral artery disease] have increased cardiovascular risk [9]. Therefore, knowledge of the presence of TOD is of major

\section{Ciomed Central}


importance for the optimal management of subjects with arterial hypertension. However, little data exist regarding the prevalence of TOD in primary care subjects in our country. The aim of the present study was to estimate the prevalence of TOD in primary care subjects.

\section{Methods}

\section{Population}

The C.V.P.C. study (Epidemiological Cardio-Vascular Study in Primary Care) was a multi-center, cross-sectional survey which was carried out in order to determine the prevalence of TOD in subjects with hypertension in primary care. The survey included 1095 subjects with a known history of hypertension, 611 men (55.8\%) and 484 women (44.2\%) who consecutively attended 115 Primary care physicians from 1-10-2009 until 31-10-2009. Only 21 subjects refused to take part in the study. Patient's medical history recording and physical examination was performed by the physicians that took part in the study. All data were documented in patients' records.

A detailed history for the presence of cardiovascular disease, TOD, current medication, information about other diseases and smoking habits was obtained, and a physical examination was performed. Body weight with subjects in light clothing without shoes and height was measured and body mass index (BMI) was calculated. Waist circumference was measured with a soft tape on standing, midway between the lowest rib and the iliac crest. The biochemical parameters were recorded from laboratory testing in the three months prior to consultation (or in the days after consultation if no such prior testing proved available) at local biochemical laboratories.

Blood pressure was measured three consecutive times, one minute in apart, in the sitting position after 5 minutes rest period using an appropriate cuff size. All the measurements performed using the A \& D UA-705 Upper Arm Blood Pressure Monitor The mean values of the last 2 measurements was calculated and used in the analysis. Arterial hypertension was defined according to the current guidelines [10], when systolic was $\geq 140 \mathrm{mmHg}$ or and/or diastolic blood pressure was $\geq 90 \mathrm{mmHg}$ or when the patients were on antihypertensive treatment. In addition the type of the antihypertensive treatment was recorded. The controlled hypertension definition was based on systolic blood pressure $\leq 140 \mathrm{mmHg}$ and diastolic blood pressure $\leq 85 \mathrm{mmHg}$ in subjects taking antihypertensive medications.

Dyslipidemia was defined when patients were on statin treatment. CAD was defined as presence of angina, history of previous myocardial infarction, positive stress testing, revascularization procedures or stenosis $>50 \%$ at the coronary arteries. DM was self-reported and defined as current use of antidiabetic treatment. Renal impairment was defined as plasma creatinine levels $\geq 1.3 \mathrm{mg} / \mathrm{dl}$.
Microalbuminuria was defined as 24 hour urinary albumin of 30-300 mg/dl. Presence of LVH and increased carotid IMT were reported according to subject's recent ultrasound examination. Subjects having three or more of the following criteria (according to the NCEP ATP III report) [11], were defined as having the metabolic syndrome (MS): abdominal obesity (waist circumference $>102 \mathrm{~cm}$ in men and $>88 \mathrm{~cm}$ in women), triglycerides $\geq 150 \mathrm{mg} / \mathrm{dl}$, HDL cholesterol: $\leq 40 \mathrm{mg} / \mathrm{dl}$ in men and $\leq 50 \mathrm{mg} / \mathrm{dl}$ in women, high blood pressure: $\geq 130 /$ $85 \mathrm{mmHg}$ or use of antihypertensive drugs and high fasting plasma glucose: $\geq 100 \mathrm{mg} / \mathrm{dl}$ or treatment for diabetes mellitus. Measurement of carotid IMT was performed by carotid ultrasound examination that measured the thickness of the intimal and medial layers of the arterial wall (IMT $>0.9 \mathrm{~mm}$ in the common carotid artery is a known cardiovascular risk factor) [12]. Retinal examination was carried out by experienced ophthalmologists with no prior knowledge of the participants' blood pressure level.

The study protocol was reviewed by the bioethical committee of the Hellenic Association of Research and Continuing Education in Primary Care and a written consent was obtained from all participants.

\section{Statistical analyses}

Data are expressed as mean \pm standard deviation (SD). Student's $t$-tests and pearson's $\chi^{2}$ test was used to compare between-groups differences. Logistic regression analysis with a backward stepwise approach was employed to identify variables associated with TOD. Relative risks (RR) were calculated from logistic regression models. Any P value $\leq 0.05$ (two-tailed) was considered statistically significant. Data were analyzed using SPSS v 15.0 (SPSS, Chicago, IL, USA).

\section{Results}

The basic demographic characteristics of the study subjects are showed in Table 1. Two hundred eighty one (25.7\%) subjects had a family history of cardiovascular disease and $28.4 \%(\mathrm{n}=311)$ patients had MS. Smokers were $38.9 \%$ of the study population. The most frequent co-morbidities were DM (25.8\%) and dyslipidemia (59.5\%); followed by peripheral artery disease (12.2\%), CAD (11.9\%), retinopathy (7.2\%), heart failure (7.0\%) and cerebrovascular disease (4.9\%).

\section{Blood pressure control}

$56.8 \%$ of the subjects, $(n=622)$ had blood pressure levels that were considered well-controlled $(<140 / 85$ $\mathrm{mmHg}$ ). The above targets for blood pressure were achieved by $63.1 \%$ of the subjects with CAD, $53.5 \%$ of the subjects with TOD and $46.6 \%$ of the diabetic subjects. Of the subjects achieved blood pressure levels 
Table 1 Characteristics of the studied population [data are showed as Mean \pm SD or $n$ (\%)]

\begin{tabular}{|c|c|c|c|c|}
\hline & Men & Women & All & $P^{*}$ \\
\hline Mean age (years) & $61.7 \pm 10.1$ & $62.1 \pm 10.8$ & $61.9 \pm 10.5$ & 0.46 \\
\hline Systolic blood pressure $(\mathrm{mmHg})$ & $137.3 \pm 18.6$ & $134.2 \pm 14.7$ & $138.7 \pm 17.4$ & 0.54 \\
\hline Diastolic blood pressure (mmHg) & $84.5 \pm 11.2$ & $80.6 \pm 8.7$ & $83.3 \pm 10.3$ & 0.62 \\
\hline Body mass index $\left(\mathrm{kg} / \mathrm{m}^{2}\right)$ & $29.0 \pm 8.2$ & $28.8 \pm 13.2$ & $28.9 \pm 10.6$ & 0.71 \\
\hline Waist circumference $(\mathrm{cm})$ & $104.3 \pm 10.3$ & $102.5 \pm 10.0$ & $104.0 \pm 10.2$ & 0.49 \\
\hline Smoking status & $305(50.6)$ & $121(25.6)$ & $426(38.9)$ & $<0.001$ \\
\hline Diabetes mellitus & $160(26.6)$ & $123(26.0)$ & $283(25.8)$ & 0.81 \\
\hline Metabolic syndrome & $174(29.1)$ & $137(29.2)$ & $311(28.4)$ & 0.96 \\
\hline Heart failure & $40(6.6)$ & $37(7.8)$ & $77(7.0)$ & 0.46 \\
\hline Coronary artery disease & $102(16.9)$ & $28(5.9)$ & $130(11.9)$ & $<0.001$ \\
\hline Dyslipidemia & $366(60.4)$ & $285(59.6)$ & $651(59.5)$ & 0.97 \\
\hline Stroke & $29(4.8)$ & $25(5.2)$ & $54(4.9)$ & 0.06 \\
\hline Peripheral artery disease & $76(12.6)$ & $58(12.3)$ & $134(12.2)$ & 0.89 \\
\hline
\end{tabular}

P-values refer to the comparisons between two genders.

$12.5 \%$ were on single anti-hypertensive agent, $60.0 \%$ on dual anti-hypertensive agents and $27.5 \%$ were prescribed $\geq 3$ anti-hypertensive drugs.

\section{Target organ damage}

Of the total study population, $44.5 \%(n=487)$ had documented TOD (33.0\% had LVH, 21.8\% increased carotid IMT, $11.0 \%$ elevated plasma creatinine levels and $14.6 \%$ microalbuminuria). TOD was more prevalent in males than in females $(49.1 \%$ vs. $43.0 \%$, respectively, $\mathrm{P}=0.05)$. In addition, males had more often increased carotid IMT than females $(25.5 \%$ vs. $18.8 \%$, respectively, $\mathrm{P}=0.009)$. On the contrary, females had more often microalbuminuria $(17.5 \%$ vs. $13.4 \%$, respectively, $\mathrm{P}=0.06)$ than males. No differences were observed between the two genders regarding $\mathrm{LVH}$ (34.5\% vs. $31.9 \%$, respectively, $\mathrm{P}=0.35$ ) and elevated plasma creatinine levels (10.3\% vs. $12.9 \%$, respectively, $\mathrm{P}=0.21$ ) (Table 2 ).

Of the subjects with dyslipidemia, 53.5\% ( $\mathrm{n}=348$ ) had documented TOD (41.0\% had LVH, 27.5\% increased carotid IMT, $14.3 \%$ elevated plasma creatinine levels and $18.6 \%$ microalbuminuria). Of the subjects with MS, $61.7 \%$ $(\mathrm{n}=192)$ had documented TOD (49.2\% had LVH, 29.9\% increased carotid IMT, $21.5 \%$ elevated plasma creatinine levels and $30.9 \%$ microalbuminuria). Of the diabetic subjects, $62.2 \%(\mathrm{n}=176)$ had documented TOD $(45.9 \%$ had LVH, 33.2\% increased carotid IMT, 27.2\% elevated plasma creatinine levels and $36.0 \%$ microalbuminuria).
Logistic regression analysis showed associations between TOD and dyslipidemia [odds ratio (OR): 2.04, 95\% Confidence Intervals (95\% CI): 1.52-2.73, P < 0.001], presence of MS $(\mathrm{OR}=1.64,95 \% \mathrm{CI}: 1.16-2.31, \mathrm{P}=$ 0.005), DM (OR = 1.93, 95\% CI: 1.36-2.7, $\mathrm{P}<0.001)$ and $\mathrm{CAD}(\mathrm{OR}=4.06,95 \% \mathrm{CI}: 2.44-6.76, \mathrm{P}<0.001)$.

\section{Discussion}

In the present study we showed that a significant proportion of hypertensive subjects in primary care had documented associated TOD. LVH was the most prevalent TOD followed by increased carotid IMT and renal impairment. In addition, TOD was more prevalent in hypertensive males than in females. Studies from different populations have demonstrated a high percentage of TOD among hypertensive subjects [13-19]. Studies from the U.S.A. [13], Africa [14-17] and Europe [18,19] have showed high prevalence of TOD in hypertensive subjects. In addition, in African hypertensive subjects, males had higher odds of developing TOD compared to females [14]. It is well established that presense, even subclinical, of TOD is associated with increased cardiovascular mortality [4-9]. In addition, hypertensive subjects with LVH [4], increased IMT [5] and microalbuminuria [6-9] show increased cardiovascular risk. Therefore, presence of TOD has an important role in the treatment of hypertensive subjects and the prevention of cardiovascular disease $[2,3]$. Knowledge of prevalence of TOD in primary care

Table 2 Prevalence of target organ damage among hypertensive subjects attending primary care

\begin{tabular}{lcccc}
\hline Target organ damage & Men & Women & All & $P^{*}$ \\
\hline Left ventricular hypertrophy & $207(34.5)$ & $154(31.9)$ & $361(33.0)$ & 0.35 \\
Increased carotid intima media thickness & $152(25.5)$ & $87(18.8)$ & $239(21.8)$ & 0.009 \\
Elevated plasma creatinine levels & $61(10.3)$ & $59(12.9)$ & $120(11.0)$ & 0.22 \\
Microalbuminuria & $79(13.4)$ & $81(17.5)$ & $160(14.6)$ & 0.06 \\
\hline
\end{tabular}

P-values refer to the comparisons between two genders. 
might help to early detection and intensive treatment of subjects at high cardiovascular risk.

It is known that TOD already exists in newly diagnosed hypertensive subjects [20]. A recent study in our country showed that subjects with white coat and masked hypertension had TOD in terms of LVH and increased carotid IMT [21]. It is noteworthy, that even at early stages of hypertension TOD is present resulting at increased cardiovascular risk among hypertensive subjects [20,21]. Confirming previous studies, we showed that $\mathrm{LVH}$ was the most prevalent TOD in hypertensive subjects [13,15-17] followed by renal impairment $[13,19]$.

Logistic regression analysis showed associations between TOD and presence of MS, dyslipidemia, DM and CAD. In hypertensive subjects MS, as a clustering of cardiovascular risk factors, amplifies TOD [22-24]. A recent study showed that the risk of $\mathrm{LVH}$, carotid abnormalities and microalbuminuria increased by the presence of MS even after adjusting for several confounders [22]. Another study found a strong association between MS and TOD by showing that a clustering of two or three markers of TOD is the prevalent cardiovascular phenotype in MS hypertensive subjects [24]. A study in this elderly non-diabetic hypertensive subjects showed that the presence of MS was independently related to a greater prevalence of TOD and established cardiovascular disease [24].

In addition, $\mathrm{DM}$ and $\mathrm{CAD}$ per se have been associated with TOD in hypertensive subjects $[16,19]$. TOD tends to be more prevalent in hypertensive diabetic patients than in non-diabetics [25], as is the case in subjects with MS [26]. Another study found a relationship between TOD and established cardiovascular disease [19]. In fact, the prevalence of established cardiovascular disease was twice as great in hypertensive subjects with LVH and renal impairment [19]. Finally, despite previous findings, in the present study we failed to demonstrate any association between TOD and blood pressure levels $[14,15]$.

\section{Limitations}

The present study has its limitations. In the present study only subjects with a known history of arterial hypertension where included and therefore a selection bias could not be avoided. In addition, information regarding the duration of antihypertensive treatment and diabetes are missing. Another limitation is that measurements were obtained by biochemical laboratories at different regions and not a central one.

\section{Conclusion}

In conclusion, a significant proportion of hypertensive subjects in primary care had documented associated TOD, with LVH being the most prevalent TOD. The above finding emphasizes the important role of the primary care clinicians to the early detection, treatment and control of high blood pressure that might help to reducing overall cardiovascular risk.

\section{Acknowledgements}

The study was supported by a grant of Menarini Hellas.

\section{Author details}

${ }^{1}$ Hellenic Association of Research and Continuing Education in Primary Care, Athens, Greece. ${ }^{2} 3$ rd Department of Internal Medicine and Center of Diabetes, General Hospital of Nikaia "Ag. Panteleimon" - Piraeus, Greece. ${ }^{3}$ Nemea Health Center, Nemea, Korinthia, Greece. ${ }^{4}$ Department of General Practice, Health Centre of Kalivia, Kalivia-Lagonisi, Athens, Greece.

\section{Authors' contributions}

$E S, C P, A G, O A, H K$ and MS participated in the collection of the data. AP, ES, AS and CT participated in the design of the study and performed the statistical analysis and drafted the manuscript. All authors read and approved the final manuscript.

\section{Competing interests}

The authors declare that they have no competing interests.

Received: 12 February 2011 Accepted: 14 July 2011

Published: 14 July 2011

\section{References}

1. Kaplan NM: Hypertension in the population at large. In Kaplan's Clinical Hypertension.. 8 edition. Edited by: Kaplan NM. Baltimore, Lippincott Williams 2002:1-2.

2. Ogden LG, He J, Lydick E, Whelton PK: Long-term absolute benefit of lowering blood pressure in hypertensive patients according to the JNC VI risk stratification. Hypertension 2000, 35:539-43.

3. Leoncini G, Sacchi G, Viazzi F, Ravera M, Parodi D, Ratto E, Vettoretti S, Tomolillo C, Deferrari G, Pontremoli R: Microalbuminuria identifies global cardiovascular risk in essential hypertension: An artificial neural networkbased approach. J Hypertens 2002, 20:1315-21.

4. Ghali JK, Liao Y, Cooper RS: Influence of left ventricular geometric patterns on prognosis in patients with or without coronary artery disease. J Am Coll Cardiol 1998, 31:1635-40.

5. O'Leary DH, Polak JF, Kronmal RA, Manolio TA, Burke GL, Wolfson SK Jr: Carotid-artery intima and media thickness as a risk factor for myocardial infarction and stroke in older adults. Cardiovascular Health Study Collaborative Research Group. N Engl J Med 1999, 340:14-22.

6. Pontremoli R: Microalbuminuria in essential hypertension-Its relation to cardiovascular risk factors. Nephrol Dial Transplant 1996, 1:2113-5.

7. Pontremoli R, Ravera M, Bezante GP, Viazzi F, Nicolella C, Berruti V, Leoncini G, Del Sette M, Brunelli C, Tomolillo C, Deferrari G: Left ventricular geometry and function in patients with essential hypertension and microalbuminuria. J Hypertens 1999, 17:993-1000.

8. Jensen JS, Feldt-Rasmussen B, Strandgaard S, Schroll M, Borch-Johnsen K: Arterial hypertension, microalbuminuria, and risk of ischemic heart disease. Hypertension 2000, 35:898-903.

9. Mancia G, De Backer G, Dominiczak A, Cifkova R, Fagard R, Germano G, Grassi G, Heagerty AM, Kjeldsen SE, Laurent S, Narkiewicz K, Ruilope L, Rynkiewicz A, Schmieder RE, Struijker Boudier HA, Zanchetti A, Vahanian A, Camm J, De Caterina R, Dean V, Dickstein K, Filippatos G, Funck-Brentano C, Hellemans I, Kristensen SD, McGregor K, Sechtem U, Silber S, Tendera M, Widimsky P, Zamorano JL, Kjeldsen SE, Erdine S, Narkiewicz K, Kiowski W, Agabiti-Rosei E, Ambrosioni E, Cifkova R, Dominiczak A, Fagard R, Heagerty AM, Laurent S, Lindholm LH, Mancia G, Manolis A, Nilsson PM, Redon J, Schmieder RE, Struijker-Boudier HA, Viigimaa M, Filippatos G, Adamopoulos S, Agabiti-Rosei E, Ambrosioni E, Bertomeu V, Clement D, Erdine S, Farsang C, Gaita D, Kiowski W, Lip G, Mallion JM, Manolis AJ, Nilsson PM, O'Brien E, Ponikowski P, Redon J, Ruschitzka F, Tamargo J, van Zwieten P, Viigimaa M, Waeber B, Williams B, Zamorano JL: The task force for the management of arterial hypertension of the European Society of Hypertension, The task force for the management of arterial 
hypertension of the European Society of Cardiology. Guidelines for the management of arterial hypertension. Eur Heart J 2007, 28:1462-536

10. Chobanian AV, Bakris GL, Black HR, Cushman WC, Green LA, Izzo JL Jr, Jones DW, Materson BJ, Oparil S, Wright JT Jr, Roccella EJ: Joint National Committee on Prevention, Detection, Evaluation, and Treatment of High Blood Pressure. National Heart, Lung, and Blood Institute; National High Blood Pressure Education Program Coordinating Committee. Seventh report of the Joint National Committee on Prevention, Detection, Evaluation, and Treatment of High Blood Pressure. Hypertension 2003, 42:1206-52.

11. Report of the Expert Committee on the Diagnosis and Classification of Diabetes Mellitus. Diabetes Care 1997, 20:1183-97.

12. Pignoli P, Tremoli E, Poli A, Oreste P, Paoletti R: Intimal plus medial thickness of the arterial wall: A direct measurement with ultrasound imaging. Circulation 1986, 74:1399-406.

13. Post WS, Hill MN, Dennison CR, Weiss JL, Gerstenblith G, Blumenthal RS High prevalence of target organ damage in young, African American inner-city men with hypertension. J Clin Hypertens (Greenwich) 2003, 5:24-30

14. Addo J, Smeeth L, Leon DA: Hypertensive target organ damage in Ghanaian civil servants with hypertension. PLoS One 2009, 4:e6672.

15. Ayodele OE, Alebiosu CO, Salako BL, Awoden OG, Abigun AD: Target organ damage and associated clinical conditions among Nigerians with treated hypertension. Cardiovasc J S Afr 2005, 16:89-93.

16. Ayodele OE, Alebiosu CO, Akinwusi PO, Akinsola A, Mejiuni A: Target organ damage and associated clinical conditions in newly diagnosed hypertensives attending a tertiary health facility. Niger J Clin Pract 2007, 10:319-25

17. Peer N, Steyn K, Dennison CR, Levitt NS, Nyo MT, Nel JH, Commerford PJ, Fourie JM, Hill MN: Determinants of target organ damage in black hypertensive patients attending primary health care services in Cape Town: the Hi-Hi study. Am J Hypertens 2008, 21:896-902.

18. Cuspidi C, Valerio C, Sala C, Esposito A, Masaidi M, Negri F, Zanchetti A, Mancia G: Prevalence and correlates of multiple organ damage in a never-treated hypertensive population: role of ambulatory blood pressure. Blood Press Monit 2008, 13:7-13.

19. Cea-Calvo L, Conthe P, Gómez-Fernández P, de Alvaro F, FernándezPérez C, RICARHD investigators: Target organ damage and cardiovascular complications in patients with hypertension and type 2 diabetes in Spain: a cross-sectional study. Cardiovasc Diabetol 2006, 5:23.

20. Salako BL, Ogah OS, Adebiyi AA, Adedapo KS, Bekibele CO, Oluleye TS, Okpechi I: Unexpectedly high prevalence of target-organ damage in newly diagnosed Nigerians with hypertension. Cardiovasc J Afr 2007, 18:77-83.

21. Kotsis V, Stabouli S, Toumanidis S, Papamichael C, Lekakis J, Germanidis G, Hatzitolios A, Rizos Z, Sion M, Zakopoulos N: Target organ damage in "white coat hypertension" and "masked hypertension". Am J Hypertens 2008, 21:393-9.

22. Cuspidi C, Meani S, Valerio C, Sala C, Fusi V, Zanchetti A, Mancia G: Age and target organ damage in essential hypertension: role of the metabolic syndrome. Am J Hypertens 2007, 20:296-303.

23. Cuspidi C, Valerio C, Giudici V, Negri F, Sala C, Zanchetti A, Mancia G: Metabolic syndrome and multiple organ damage in essential hypertension. Blood Press 2008, 17:195-203.

24. Navarro J, Redón J, Cea-Calvo L, Lozano JV, Fernández-Pérez C, Bonet A, González-Esteban J: Metabolic syndrome, organ damage and cardiovascular disease in treated hypertensive patients. The ERIC-HTA study. Blood Press 2007, 16:20-7.

25. Lozano JV, Redon J, Cea-Calvo L, Fernandez-Perez C, Navarro J, Bonet A, Gonzalez-Esteban J: Left ventricular hypertrophy in the Spanish hypertensive population. The ERIC-HTA study. Rev Esp Cardiol 2006, 59:136-42.

26. Mule G, Nardi E, Cottone S, Cusimano P, Volpe V, Piazza G, Mongiovi R, Mezzatesta G, Andronico G, Cerasola G: Influence of metabolic syndrome on hypertension-related target organ damage. J Intern Med 2005, 257:503-13.

\section{Pre-publication history}

The pre-publication history for this paper can be accessed here:

http://www.biomedcentral.com/1471-2296/12/75/prepub doi:10.1186/1471-2296-12-75

Cite this article as: Papazafiropoulou et al.: Prevalence of target organ damage in hypertensive subjects attending primary care: C.V.P.C. study (epidemiological cardio-vascular study in primary care). BMC Family Practice $201112: 75$

\section{Submit your next manuscript to BioMed Central and take full advantage of:}

- Convenient online submission

- Thorough peer review

- No space constraints or color figure charges

- Immediate publication on acceptance

- Inclusion in PubMed, CAS, Scopus and Google Scholar

- Research which is freely available for redistribution

Submit your manuscript at www.biomedcentral.com/submit
C Biomed Central 